10.12737/article_59ad0b829e3b49.78457549

УДК 347.721 .4

ПРОБЛЕМЫ ТЕХНИЧЕСКОГО ОБЕСПЕЧЕНИЯ СЕЛЬСКОГО ХОЗЯЙСТВА

РЕСПУБЛИКИ ТАТАРСТАН

Мухаметгалиев Ф.Н., Садриева Ф.Ф.

Реферат. Техническая обеспеченность предприятий агропромышленного комплекса - это один из важных факторов их производственного и экономического развития. Данный фактор имеет место быть при обработке почв, уборке и реализации продукции сельского хозяйства. Так, производство продукции растениеводства напрямую зависит от технической обеспеченности села тракторами, комбайнами и прочими сельхозмашинами, позволяющими применять и своевременно выполнять все агрономические требования. Основной причиной ухудшения состояния материально-технической базы является отсутствие финансовых средств у хозяйств для приобретения техники и оборудования, а также ослабление поддержки государства, сокращение объемов инвестиций на развитие сельского хозяйства. От своевременного и полного обеспечения сельского хозяйства материально-техническими ресурсами, а также от эффективности их использования зависят объемы производства сельскохозяйственной продукции и результаты деятельности сельскохозяйственных организаций. Оптимальное формирование и рациональное использование материально-технической базы сельского хозяйства оказывает непосредственное влияние на результаты деятельности всего агропромышленного комплекса. Эффективное использование сельскохозяйственных ресурсов возможно при повышении интенсивности производства сельского хозяйства на основе высокоразвитой материально-технической базы. В настоящее время на сельскохозяйственных предприятиях не создан комплекс машин для механизации сельскохозяйственного производства, соответствующий достижениям науки и техники в этой области, а использовать имеющуюся устаревшую материально-техническую базу, как основу повышения интенсивности сельскохозяйственного производства в современных условиях, очень сложно. В связи с этим особую актуальность в современных условиях приобретает поиск путей технического перевооружения и комплексной механизации сельского хозяйства.

Ключевые слова: сельское хозяйство, материально-техническая база, техническое обеспечение, государственная поддержка.

Введение. Сельское хозяйство Татарстана играет важную роль в развитии экономики республики, так как формирует продовольственную базу региона. В отрасли занято 83,7 тыс. человек, что составляет $6,2 \%$ экономически активного населения республики. Республика Татарстан специализируется на выращивании зерновых культур, сахарной свеклы и картофеля, а также на производстве мяса, молока и яиц. Сельхозугодия занимают 4,4 млн га земель (65\% территории Татарстана), из них $77 \%$ - пашня, 23\% -площади естественных пастбищ и сенокосов.

Агропромышленный комплекс республики обеспечивает население основными продуктами питания собственного производства. Показатели потребления продовольствия на душу населения в Татарстане значительно выше, чем в среднем по России.

Сельское хозяйство Татарстана занимает одно из ведущих мест среди регионов Российской Федерации. Республика Татарстан, имея чуть более $2 \%$ сельхозугодий России, производит $8 \%$ валового сбора зерна, является крупнейшим производителем мяса, молока, яиц. В структуре валового регионального продукта сельское хозяйство занимает четвертое место $(7,9 \%)$, уступая промышленности, сектору услуг и строительству. В отрасли функциони- руют государственные и частные сельхозпредприятия. Более половины сельхозпродукции дают малые формы - фермерские хозяйства (4,6\%), личные подсобные хозяйства $(48,7 \%)$.

Анализ и обсуждение результатов. Современное сельское хозяйство должно основываться на солидной материальнотехнической базе.

Материально- техническая база сельского хозяйства - это совокупность материальных, вещественных элементов, средств производства и орудий труда, которые используются в экономических процессах: производства, peaлизации и организации потребления. Техническая обеспеченность предприятий агропромышленного комплекса - это один из важных факторов их производственного и экономического развития. Данный фактор имеет место быть при обработке почв, уборке и реализации продукции сельского хозяйства.

От того как модернизирована материально-техническая база нашей страны зависит повышение рентабельности производства сельскохозяйственной продукции, а также конкурентоспособность отечественных сельскохозяйственных товаропроизводителей [4].

Сельское хозяйство в нашей стране имеет множество структурных проблем, для решения которых необходим ряд структурных пре- 
ЭК ОНОМИЧЕСКИЕ НА УКИ

Таблица 1 - Основные показатели развития сельского хозяйства Республики Татарстан за 2012-2016 гг. *

\begin{tabular}{|l|c|c|c|c|c|}
\hline \multirow{2}{*}{ Показатели } & \multicolumn{5}{|c|}{ Годы } \\
\cline { 2 - 6 } $\begin{array}{l}\text { Производство, тыс. т: } \\
\text { Зерно }\end{array}$ & 2012 & 2013 & 2014 & 2015 & 2016 \\
\hline Картофель & 2990,5 & 2611,5 & 3366,0 & 3367,7 & 4307,2 \\
\hline Овощи & 1376,4 & 1323,0 & 1315,8 & 1589,7 & 1440,6 \\
\hline сахарная свекла & 327,9 & 329,4 & 357,0 & 385,3 & 413,3 \\
\hline Молоко & 2010,8 & 2109,8 & 1408,4 & 2011,8 & 2319,2 \\
\hline скот и птица (на убой.) & 1888,4 & 1751,6 & 1728,3 & 1750,1 & 1765,1 \\
\hline яйца, млн шт. & 452,2 & 477,2 & 465,9 & 468,5 & 486,2 \\
\hline $\begin{array}{l}\text { Валовая продукция сельского хозяйства, } \\
\text { млрд. руб. }\end{array}$ & 1120,2 & 1073,0 & 1104,8 & 1170,6 & 1135,1 \\
\hline Сумма прибыли (+), убытка (-), млн руб. & 150,1 & 160,6 & 186,0 & 213,7 & 238,6 \\
\hline Уровень рентабельности, \% & 5641,2 & 2571,1 & 9834,8 & 12683 & 7403,6 \\
\hline
\end{tabular}

* по данным Министерства сельского хозяйства и продовольствия РТ

Таблица 2 - Парк основных видов техники в сельскохозяйственных организациях (на конец года; тыс. штук)

\begin{tabular}{|l|c|c|c|c|c|}
\hline Виды техники & 2011 & 2012 & 2013 & 2014 & 2015 \\
\hline Тракторы & & & & \\
\hline Комбайны: & 11,7 & 11,3 & 10,7 & 10,6 & 10,5 \\
\hline зерноуборочные & & & & & \\
\hline картофелеуборочные & 2,9 & 2,8 & 2,6 & 2,5 & 2,6 \\
\hline кормоуборочные & 0,1 & 0,1 & 0,1 & 0,1 & 0,1 \\
\hline $\begin{array}{l}\text { Свеклоуборочные машины (без } \\
\text { ботвоуборочных) }\end{array}$ & 0,9 & 0,8 & 0,8 & 0,8 & 0,7 \\
\hline Косилки & 0,2 & 0,1 & 0,1 & 0,1 & 0,1 \\
\hline Пресс-подборщики & 1,5 & 1,4 & 1,3 & 1,3 & 1,3 \\
\hline $\begin{array}{l}\text { Разбрасыватели твердых } \\
\text { минеральных удобрений }\end{array}$ & 0,5 & 0,4 & 0,4 & 0,4 & 0,4 \\
\hline
\end{tabular}

1) Без тракторов, на которых смонтированы землеройные, мелиоративные и другие машины.

образований. Одной из таких проблем, является проблема технической оснащенности сельскохозяйственных предприятий.

Показатели таблицы 1 свидетельствуют о стабильно высоких результатах деятельности сельскохозяйственных товаропроизводителей республики. За последние 5 лет обеспечен постоянный рост объема производства по основным видам сельскохозяйственной продукции, 93\% сельскохозяйственных организаций работают рентабельно. В целом прослеживается положительная динамика в отрасли, наблюдается ежегодный рост объемов производства. Существенная роль в этом принадлежит политике государственной поддержки отечественного сельхозпроизводителя. Государственной программой «Развития сельского хозяйства и регулирования рынков сельскохозяйственной продукции, сырья и продовольствия в Республике Татарстан на 2013 - 2020 годы» (Программа) [1] поставлена задача при- роста валовой продукции сельского хозяйства до 2020 г. на 18\% к уровню 2016 года.

Очевидно, что для обеспечения устойчивого экономического развития и повышения конкурентоспособности сельского хозяйства необходим переход от инерционных к инновационным методам хозяйствования, которые предполагают освоение технических и технологических инноваций, опирающихся на применение ресурсосберегающих техники и технологий. Решение данной задачи и обеспечение эффективной деятельности сельскохозяйственных организаций без укрепления материально-технической базы, в частности, технической модернизации сельского хозяйства не представляется возможным.

Состояние современной технической оснащенности аграрного производства Республики Татарстан характеризуется продолжающимся сокращением общего количества техники по всем видам силовых и сельскохозяйственных 
Э К О О МИ ЧЕСКИЕ НА УКИ

Таблица 3 - Возрастной состав основных видов сельскохозяйственной техники в Республике Татарстан на 01.01.2017 г., \%*

\begin{tabular}{|l|c|c|c|c|}
\hline \multirow{2}{*}{ Виды техники } & \multirow{2}{*}{ Количество, ед } & \multicolumn{3}{|c|}{ Срок эксплуатации, лет } \\
\cline { 3 - 5 } & & до 3 & от 3 до 10 & более 10 \\
\hline Тракторы & 10,5 & 8 & 32 & 60 \\
\hline Зерноуборочные комбайны: & 2,6 & 13 & 47 & 40 \\
\hline Кормоуборочные комбайны: & 0,7 & 17 & 43 & 40 \\
\hline Посевные комплексы & 0,6 & 20 & 72 & 8 \\
\hline
\end{tabular}

* по данным Министерства сельского хозяйства и продовольствия РТ

машин. По данным Татарстанстата, в Республике Татарстан в период с 2011 по 2015 годы произошло сокращение парка тракторов на 1,2 тыс. единиц, зерноуборочных комбайнов - на 0,3 тыс. единиц, кормоуборочных комбайнов на 0,2 тыс. единиц [5].

Главная причина - низкая доходность сельхозпроизводства, не позволяющее осуществлять большинству производителей расширенное, а значительной его части - простое воспроизводство.

Тревожным явлением остается увеличение доли техники со сроком службы более 10 лет. В основу тракторного парка (58\%) все еще составляют морально устаревшие модели, такие как К-700, Т-150К, ДТ-75, МТ3-80/82, которые работают за пределами установленных амортизационных сроков. Анализ возрастного состава основных видов сельскохозяйственной техники приведен в таблице 3 .

Анализ возрастного состава основных видов сельскохозяйственной техники показывает, что по состоянию на начало 2017 года большая часть всех видов машин работает за пределами амортизационных сроков службы.

В дальнейшем материально-техническая база будет обновляться при реализации государственной программы «Развитие сельского хозяйства и регулирование рынков сельскохозяйственной продукции, сырья и продовольствия в Республике Татарстан на 2013-2020 годы». Она предусматривает выделение из регионального бюджета 12,6 млрд руб. на приобретение новых 6,2 тыс. тракторов, 2160 зерноуборочных комбайнов, 680 кормоуборочных комбайнов, 40 свеклоуборочных комбайнов, 540 самоходных косилок, 630 грузовых автомобилей, 1200 комплектов животноводческого оборудования [1]. В рамках выполнения подпрограммы «Техническая и технологическая модернизация, инновационное развитие» республикой ежегодно приобретается сельскохозяйственные машины на сумму около 6 млрд руб. при бюджетной поддержке 2 млрд руб. За четыре года реализации Программы приобретено 1421 трактор, 559 зерноубороч- ных комбайнов, 203 кормоуборочных комбайна.

Для решения данной проблемы технической оснащенности необходимо не только обновление парка сельскохозяйственных машин, но и решение проблемы развития человеческого капитала в отрасли, что подразумевает решение социально-экономических проблем на сельской местности. Очевидно, что сельское хозяйство - отрасль со слабой инвестиционной привлекательностью, что не позволяет основной части товаропроизводителей в этой отрасли в полной мере использовать достижения НТП для повышения эффективности и конкурентоспособности производимой ими продукции. Проблема в том, что это, по сути, замкнутый круг: сельское хозяйство не станет инвестиционно привлекательным без достаточного финансирования. Поэтому здесь важнейшую роль должно сыграть именно государство. При поддержке государства, вероятно, не только увеличение спроса на внутреннем и внешнем зерновом рынках влияет на рост производства в стране сельхозтехники. Есть и другой мощный стимулирующий фактор - выделяемые государством субсидии машиностроителям с условием, что они предоставят аграриям солидные скидки.

Государство поддерживает продажи отечественных сельхозмашин с 2013 года. Выделены меры поддержки технической и технологической модернизации:

1. Субсидирование машиностроителей, которое предоставляет аграриям 25-30процентную скидку на технику в зависимости от региона;

2. Инструменты финансовой аренды (лизинга), которые предлагаются на федеральном и региональном уровнях.

Насколько востребован этот механизм, говорят следующие цифры: по федеральному лизингу через АО «Росагролизинг» в 2017 году планируется поставки техники на сумму 2,5 млрд руб.; по федеральной программе, предусмотренной постановлением Правительства России №1432 (программа 1432), с 25\% скидкой зарегистрировано 337 договоров на 
сумму 1,4 млрд руб.; по региональной программе «40х60» на техническую и технологическую модернизацию АПК РТ из бюджета республики ежегодно выделяется по 2 млрд руб. на субсидирование $40 \%$ стоимости приобретаемых сельхозмашин и оборудования для животноводства; по региональной программе субсидирования приобретения сельхозмашин субъектами аграрного бизнеса, находящихся в нефтяных районах РТ с участием ПАО «Татнефть» по схеме 33×33×34x (ПАО «Татнефть» Министерство сельского хозяйства и продовольствия РТ сельхозтоваропроизводители) с внесением по 100 млн руб. с каждого участника. Благодаря этим мерам стимулирования ставится задача на 2017 год довести приобретение сельхозтехники, максимально используя лизинговые сделки, на 10 млрд руб. и наращивать темпы обновления на последующие годы на 2 млрд руб. ежегодно [6; 7].

Эффективны также продукты «Россельхозбанка», других кредитных, финансовых учреждений. АО «Росагролизинг», доказав свою эффективность, по сути является институтом развития АПК в России, выполняет задачи, поставленные Правительством РФ по обеспечению отечественных сельхозтоваропроизводителей современной энергонасыщенной сельскохозяйственной техникой, высокотехнологичным оборудованием и высокопродуктивным племенным скотом. Одним из главных направлений работы компании является решение стратегических задач по обеспечению, в частности, доктрины продовольственной безопасности Российской Федерации.

Стремиться надо к тому, чтобы по обеспеченности села техникой, продуктивности полей конкурировать с передовыми странами, так как обеспеченность техникой является одним из важнейших факторов повышения урожайности.

По выводам ученых, среди основных факторов в формировании урожая 25 процентов занимают природно-климатические условия, столько же - удобрения и химические средства защиты растений, 20 процентов - семена. Остальное - 30 процентов - зависит от наличия необходимого количества сельхозтехники и оборудования для выполнения полного комплекса работ в оптимальные агротехнические сроки. В настоящее время энергообеспеченность сельскохозяйственного производства Республики Татарстан составляет 161 л.с. на 100 га посевных площадей и за последние годы имеет тенденцию к увеличению.
Обеспечение аграриев качественной, надежной, доступной по цене техникой - задача первостепенная. Сейчас получают второе дыхание селекционные работы, можно приобретать сколько угодно эффективных удобрений. Но если не будет хватать техники, будем терять не часы и дни, а недели на уборке урожая, оставлять на полях много уже выращенного.

Мощная техника, использование высокоэффективных энерго- и ресурсосберегающих технологий является залогом успешного сельского хозяйства. Современная высокотехнологичная и комфортабельная техника делает труд сельских механизаторов востребованным, повышается заработная плата, а также профессиональный уровень. Это весьма привлекательные факторы для молодых кадров, в которых так нуждается село. Поэтому министерство делает упор на внедрение такой техники и технологий.

Анализ сложившейся ситуации с техническим оснащением сельского хозяйства РТ позволяет сделать некоторые выводы.

Выводы. Уровень развития АПК по объемным показателям достаточно высокий и заметны положительные тенденции повышения экономической эффективности. Наряду с этим обеспеченность сельского хозяйства техническими средствами остается крайне низкой, значительная часть машинно-тракторного парка выработала нормативный срок службы.

Для дальнейшей технической модернизации и развития инженерно-технической сферы АПК необходимы реализация подпрограммы «Техническая и технологическая модернизация, инновационное развитие» Государственной программы «Развитие сельского хозяйства и регулирования рынков сельскохозяйственной продукции, сырья и продовольствия в Республике Татарстан на 2013-2020 годы» и дополнительные меры по привлечению инвестиций в аграрный сектор, обеспечению приоритетности цен на сельскохозяйственную продукцию, создание информационноконсультационных центров для оказания помощи в подборе и комплектации необходимой техникой, развитию агролизинга, совершенствованию механизмов льготного кредитования, необходимо усилить стимулирования субъектов аграрного бизнеса и увеличить государственную поддержку процесса технической модернизации производства современными ресурсосберегающими высокотехнологичными машинами для растениеводства, животноводства и кормопроизводства. 
1. Государственная программа «Развитие сельского хозяйства и регулирования рынков сельскохозяйственной продукции, сырья и продовольствия в Республике Татарстан 2013 - 2020 годы» - Казань, 2013.$110 \mathrm{c}$.

2. Кормаков Л.Ф., Орсик Л.С., Бахтеев Ю.Д. Рынок сельскохозяйственной техники: проблемы и решения. - М.: ФГНУ «Росинформагротех»,- 2007.- 192 с.

3. Мухаметгалиев Ф.Н., Ситдиков Р.К. Техническое оснащение АПК республики Татарстан // Сельский механизатор. -2013. -№ 11. - С. 8-9.

4. Ночёвкина Е. В. Техническая оснащенность сельского хозяйства России // Научное сообщество студентов XXI столетия. Экономические науки: сб. ст. по мат. XXXVIII междунар. студ. науч.-практ. конф. № 1(38). URL: http://sibac.info/archive/economy/1(38).

5. Территориальный орган Федеральной службы государственной статистики по Республике Татарстан: Официальный сайт [Электронный ресурс] / Режим доступа http://www.tatstat.ru

6. Файзрахманов Д.И., Мухаметгалиев Ф.Н. Проблемы адаптации сельскохозяйственных организаций Республики Татарстан к условиям ВТО // Зерновое хозяйство России. - 2014. -№2. - С. 64-67.

7. Хисматуллин М.М., Мухаметгалиев Ф.Н., Хисамов Р.Г. Лизинг техники и технологий как инструмент развития агропромышленного производства //Вестник Казанского ГАУ. - 2015. - № 2. - С. 31-35.

Сведения об авторах:

Мухаметгалиев Фарит Нургалеевич - доктор экономических наук, профессор

Садриева Фидания Фаритовна - аспирант, e-mail: sadrieva_f@mail.ru

ФГБОУ ВО «Казанский государственный аграрный университет», г. Казань, Россия.

\section{PROBLEMS OF TECHNICAL SUPPORT FOR AGRICULTURE OF THE REPUBLIC OF TATARSTAN}

Mukhametgaliev F.N., Sadrieva F.F.

Abstract. Technical supply of enterprises of agro-industrial complex is one of the important factors of their industrial and economic development. This factor takes place when processing soils, harvesting and selling agricultural products. So, the crop production directly depends on the technical provision of the village with tractors, combines and other agricultural machines, which make it possible to apply and timely fulfill all agronomic requirements.

The main reason of deterioration of the material and technical base is the lack of financial means for farms to purchase machinery and equipment, as well as weakened government support, and reduced investment in the development of agriculture. The volume of agricultural production and results of agricultural organizations depend from the timely and full provision of agriculture with material and technical resources, as well as the effectiveness of their use. Optimal formation and rational use of the material and technical base of agriculture has a direct impact on the performance of the entire agroindustrial complex. Effective use of agricultural resources is possible with increasing intensity of agricultural production on the basis of a highly developed material and technical base. At present, agricultural enterprises do not have a complex of machines for mechanizing agricultural production, that corresponds to the achievements of science and technology in this field, and it is very difficult to use the existing outdated material and technical base as the basis for increasing the intensity of agricultural production in modern conditions. In this connection, a particular urgency in modern conditions acquires the ways of technical re-equipment and integrated mechanization of agriculture.

Key words: agriculture, material and technical base, technical support, state support.

\section{References}

1. Gosudarstvennaya programma "Razvitie selskogo khozyaystva i regulirovaniya rynkov selskokhozyaystvennoy produktsii, syrya i prodovolstviya v Respublike Tatarstan 2013 - 2020 gody". (State program "Development of agriculture and regulation of markets for agricultural products, raw materials and food in the Republic of Tatarstan for 2013 - 2020"). - Kazan, 2013. P. 110

2. Kormakov L.F., Orsik L.S., Bakhteev Yu.D. Rynok selskokhozyaystvennoy tekhniki: problemy i resheniya. [The market of agricultural machinery: problems and solutions]. - M.: FGNU "Rosinformagrotekh". 2007. P. 192.

3. Mukhametgaliev F.N., Sitdikov R.K. Technical equipment of agroindustrial complex of the Republic of Tatarstan. [Tekhnicheskoe osnaschenie APK Respubliki Tatarstan]. // Selskiy mekhanizator. - Rural mechanizer. 2013. №11. P. 8-9.

4. Nochevkina E. V. Tekhnicheskaya osnaschennost selskogo khozyaystva Rossii. // Nauchnoe soobschestvo studentov XXI stoletiya. Ekonomicheskie nauki: sb. st. po mat. XXXVIII mezhdunar. stud. nauch.-prakt. konf. (Technical equipment of Russian agriculture. // Scientific community of students of the XXI century. Economics: collection of scientific articles according to the proceedings of XXXVIII International Student Scientific and Practical Conference). №1(38). Available at: http://sibac.info/archive/economy/1(38).

5. Territorialnyy organ federalnoy sluzhby gosudarstvennoy statistiki po Respublike Tatarstan: Ofitsialnyy sayt. (Territorial authority of the federal service of state statistics in the Republic of Tatarstan: Official site). Available at: http:// www.tatstat.ru

6. Fayzrakhmanov D.I., Mukhametgaliev F.N. Problems of agricultural organizations adaptation of the Republic of Tatarstan to the WTO conditions. [Problemy adaptatsii selskokhozyaystvennykh organizatsiy Respubliki Tatarstan $\mathrm{k}$ usloviyam VTO]. // Zernovoe khozyaystvo Rossii. - Grain economy of Russia. 2014. №2. P. 64-67.

7. Khismatullin M.M., Mukhametgaliev F.N., Khisamov R.G. Leasing of machinery and technologies as a tool for the development of agro-industrial production. [Lizing tekhniki i tekhnologiy kak instrument razvitiya agropromyshlennogo proizvodstva]. // Vestnik Kazanskogo gosudarstvennogo agrarnogo universiteta. - The Herald of Kazan State Agrarian University. 2015. № 2. P. 31-35.

Authors:

Mukhametgaliev Farit Nurgaleevich - Doctor of Economics, Professor

Sadrieva Fidaniya Faritovna - graduate student, e-mail: sadrieva_f@mail.ru

Kazan State Agrarian University, Kazan, Russia. 